\title{
CORRIGENDUM
}

\section{Understanding the ecology of host plant-insect herbivore interactions in the fossil record through bipartite networks-Corrigendum}

\author{
Anshuman Swain (D), S. Augusta Maccracken, William F. Fagan, \\ and Conrad C. Labandeira (D)
}

\section{DOI:10.1017/pab.2021.20}

It has been brought to our attention that there were several features of our 2021 paper in Paleobiology (Swain et al. 2021) in which certain procedures were omitted, data and results required further discussion, or one or more of our analyses could have benefited from an alternative approach. We are taking this opportunity to address, correct, and update the record, detailed below in the following points.

Rarefaction.-The rarefaction curve in figure 1A, labeled as the Williamson Drive flora, erroneously included data from all four assemblages, which are now segregated, from oldest to youngest, into the Williamson Drive (WD), Mitchell Creek Flats (MCF), Colwell Creek Pond (CCP), and South Ash Pasture (SAP) floras. These corrected rarefaction curves, listed in Figure 1, contain $84 \%$ confidence intervals. Rarefaction curves were calculated for number of specimens and the damage types (DTs) present, which remains a common practice in the field of fossil plant-insect associations (e.g., Adroit et al. 2018; Schmidt et al. 2019; Deng et al. 2020). Rarefaction curves that are scaled using surface area account for differences in leaf size and completeness (Schachat et al. 2018). However, our study did not and could not incorporate surface area into the analyses, and therefore the calculations of rarefaction curves are based on specimen number. Furthermore, there also are biologically meaningful reasons to analyze floral assemblages by specimen number. For instance, insects often avoid previously damaged leaves for undamaged leaves (Silkstone 1987; Edwards et al. 1992). We also note that for studies that analyze fossil plant-insect interactions, total and herbivorized surface area data are overwhelmingly absent (Currano et al. 2021), and other, less adequate measures such as DTs are the only ones presently available for standardization. We currently are working on a new, more finely resolved, and available metric, other than DT and surface area, for establishing standardization in fossil bipartite networks.

Interpretation of the corrected rarefaction curves differs somewhat compared with that outlined in the publication. The confidence intervals for DT richness at the WD locality overlap with those of the SAP locality and MCF locality, rather than the with the CCP locality. CCP alone has the highest richness of DTs. MCF still exhibits higher DT richness than SAP.

Specimen Details.- There are three methodological issues regarding the samples that need to be addressed. The first is the taxonomic status of the Permian plant genus, Taeniopteris, which was present in the MCF and CCP localities. In the Mitchell Creek Flats study (Schachat et al. 2015), it was stated that

there appear to be at least two forms of Taeniopteris at MCF, possibly more. Thus, throughout this paper we refer to this form genus as representing more than one natural taxon, using "spp." (p. 832)

Similarly, it was stated in the Colwell Creek Pond study that

although we are considering Taeniopteris spp. as a single species, it likely represents multiple species at CCP, based on variables such as the secondary vein angle from the midrib and the degree of bifurcation of the secondary veins. (p. 856) 


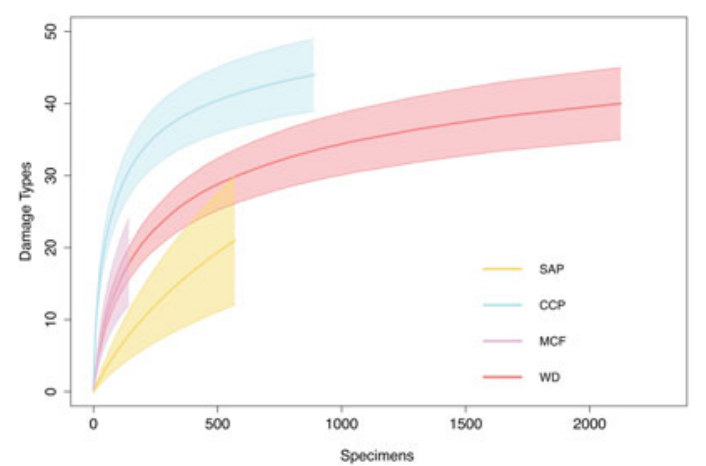

FIGURE 1. Sample-based rarefaction of each flora by damage type (DT) richness, including $84 \%$ confidence intervals, corrected from Swain et al. (2021).

In the Swain et al. (2021) paper, we acknowledge that Taeniopteris may represent multiple species. To our knowledge, the recent taxonomic status of Taeniopteris has not changed.

The second issue is the lack of inclusion of Supaia thinnfeldioides (a peltasperm) in the CCP dataset, which was not included individually in figure $2 \mathrm{~B}$ or collectively within the peltasperm assemblage of figure $3 \mathrm{~B}$ of Swain et al. (2021). The exclusion of $S$. thinnfeldioides was attributable to its rare status overall in the CCP flora. We note that exclusion of 9 specimens of $S$. thinnfeldioides is in comparison to 448 specimens of Walchia piniformis (a narrowleaved conifer, not counted), 437 specimens of Taeniopteris spp. (?cycadophyte), 421 specimens of Auritifolia waggoneri (peltasperm), 74 specimens of indeterminate broadleaf (incertae sedis), 32 specimens of Evolsonia texana (gigantopterid), 25 specimens of Sandrewia texana (peltasperm), 35 specimens of Callipterid sp. 1 (peltasperm), and 3 specimens of Sphenophyllum thonii (sphenopsid) (Schachat et al., 2014). Our post-publication inclusion of S. thinnfeldioides had no effect on the bipartite network output metrics.

The third issue is inclusion of specimens less than $0.5 \mathrm{~cm}^{2}$ at the WD locality, which is below the threshold for the three other localities. In Swain et al. (2021: p. 4), we state that "at WD, all specimens above $0.25 \mathrm{~cm}^{2}$ were analyzed," but we go on to say that

although the lower threshold at WD differs from the other three localities, this difference is not problematic, as only a small proportion of specimens at WD fall between $0.25 \mathrm{~cm}^{2}$ and $0.5 \mathrm{~cm}^{2}$.

We also note that the foliage at the WD locality is overwhelmingly dominated by the largeleaved medullosan species, Macroneuropteris scheuchzeri. The $0.25 \mathrm{~cm}^{2}$ cutoff was principally designed to include nonfoliar material, especially seeds, as stated in Xu et al. (2018: p. 33):

Because of the exceptionally good preservation of almost all the plant material from this locality, practically every identifiable leaf, stem, reproductive organ, or root mass whose size was larger than $0.25 \mathrm{~cm}^{2}$, and seeds of any size, were selected for inclusion in the dataset.

Similarly, for the SAP dataset, 64 specimens between $0.25 \mathrm{~cm}^{2}$ and $0.50 \mathrm{~cm}^{2}$ were also included in the analysis for the reasons outlined earlier. The inclusion of these specimens did not have an impact on the results, as there were zero instances of insect damage found on the specimens.

The WD dataset was supplied by the authors of the publication. A few discrepancies exist between the publication and the provided dataset. Because the publication dataset was not publicly reposited, and because this is a proof-of-concept paper and the datasets used are available for download on Dryad, we consider that issues such as the three mentioned earlier, do not affect the results of our analyses.

Finally, we are changing the second sentence in the "Acknowledgments" section of to the following: "We thank Q.-Q. Xu, W. A. DiMichele, D. Chaney, A. Rulis, J.-H. Jin, J. Gordon, M. Halthore, S. Levi, and J. Alvarez for obtaining data from the four analyzed localities."

Network Properties. - We directly used the data in unaltered form from their GitHub repository, and the data sources are cited in both our work and the original meta-analyses. A major issue raised by the reader was misplaced and involves scoring of the link weights in the network analysis as "1." The link weights are scored as " 1 " in the network analyses because many of the networks in the accumulated dataset are unweighted and, consequently, so are many 
of the metrics used for their comparison with fossil food webs. Those network properties that were meaningful for host plant-DT networks were robust to sample size and noise. Many of the network properties were not significant with respect to sample size and consequently were not listed in table 1 of Swain et al. (2021).

Broader Methodological Issues.-As this study provides the first published bipartite networks of fossil insect damage data, it raises several topics that are analyzed at greater length in a separate study in which we discuss fossil bipartite webs in the context of network science (Currano et al. 2021). There are five issues that are relevant here. First, what is the appropriate role for bootstrapping of fossil data that may reflect more investigator bias rather than the bias of the original population from which the sample was drawn? Second, how are valid error margins established on the interaction strengths of links? Third, which network properties are determined to be insensitive versus sensitive to sample size? Fourth, which network properties are relevant in the context of the full food web versus which network properties can be established using a portion of the full web, such as those of a bipartite network web? Fifth, what network properties need to be present for valid trophic comparisons of a modern versus a fossil bipartite network food web? Based on discussions with colleagues, we understand that the methods explored in our paper (Swain et al. 2021) can help us to tease apart the intricacies and interdependent nature of host plant-DT associations, as our methods consider the complexity of all observed interactions together. Previous quantitative approaches lacked this capability, as they dealt with bulk or lumped statistics such as averages or richness metrics. This refocus has a high potential for expanding knowledge about the trophic dynamics of fossil herbivory. Many of these issues are addressed and analyzed in a recently published study (Currano et al. 2021) and will be explored further in future contributions by us and others.

\section{Literature Cited}

Adroit, B., V. Girard, L. Kunzmann, J. F. Terral, and T. Wappler. 2018. Plant-insect interactions patterns in three European paleoforests of the late-Neogene-early-Quaternary. PeerJ 6:e5075.

Currano, E. D., Azevedo-Schmidt, L. E., Maccracken, S. A., and Swain, A. 2021. Scars on fossil leaves: an exploration of ecological patterns in plant-insect herbivore associations during the Age of Angiosperms. Palaeogeography, Palaeoclimatology, Palaeoecology. https: / / doi.org/10.1016/j.palaeo.2021.110636.

Deng, W., T. Su, T. Wappler, J. Liu, S. Li, J. Huang, H. Tang, S. S. Low, T. Wang, H. Xu, P. Liu, and Z. Zhou. 2020. Sharp changes in plant diversity and plant-herbivore interactions during the Eocene-Oligocene transition on the southeastern Qinghai-Tibetan Plateau. Global and Planetary Change 194:103293.

Edwards, P. J., S. D. Wratten, and E. A. Parker. 1992. The ecological significance of rapid wound-induced changes in plants: insect grazing and plant competition. Oecologia 91:266-272.

Schachat, S. R., C. C. Labandeira, J. Gordon, D. Chaney, S. Levi, M. S. Halthore, and J. Alvarez. 2014. Plant-insect interactions from Early Permian (Kungurian) Colwell Creek Pond, northcentral Texas: the early spread of herbivory in clastic environments. International Journal of Plant Sciences 175:855-890.

Schachat, S., C. C. Labandeira, and D. S. Chaney. 2015. Insect herbivory from early Permian Mitchell Creek Flats of northcentral Texas: opportunism in a balanced component community. Palaeogeography, Palaeoclimatology, Palaeoecology 440:830-847.

Schachat, S. R., C. C Labandeira, and S. A. Maccracken. 2018. The importance of sampling standardization for comparisons of insect herbivory in deep time: a case study from the late Paleozoic. Royal Society Open Science 5:171991. https:/ / doi.org/10.1098/rsos.171991.

Schmidt, L. E. A., R. E. Dunn, J. Mercer, M. Dechesne, and E. D. Currano. 2019. Plant and insect herbivore community variation across the Paleocene-Eocene boundary in the Hanna Basin, southeastern Wyoming. PeerJ 7:e7798.

Silkstone, B. E. 1987. The consequences of leaf damage for subsequent insect grazing on birch (Betula spp.). Oecologia 74:149-152. Swain, A., S. A. Maccracken, W. F. Fagan, and C. C. Labandeira. 2021. Understanding the ecology of plant-insect herbivore interactions through bipartite networks. Paleobiology 47, https://doi. org/10.1017/pab.2021.20.

Xu, Q. Q., J. Jin, and C. C. Labandeira. 2018. Williamson Drive: herbivory of a north-central Texas flora of latest Pennsylvanian age showing discrete component community structure, early expansion of piercing and sucking, and plant counterdefenses. Review of Palaeobotany and Palynology 251:28-72. 